\title{
GEOGRAFIA, CIÊNCIA... ARTE. NOVOS OLHARES...
}

\author{
GEOGRAFÍA, CIENCIA ... ARTE. NUEVAS MIRADAS ...
}

GEOGRAPHY, SCIENCE ... ART. NEW VIEWS ...

\author{
Maria Auxiliadora da Silva ${ }^{1}$ \\ Universidade Federal da Bahia, Salvador, Brasil
}

\begin{abstract}
Resumo: A experiência da Disciplina O Espaço Geográfico na Literatura, do programa de Mestrado em Geografia, da Universidade Federal da Bahia, no instigante e prazeroso diálogo entre a Geografia e a Arte, será abordada nas obras Visões Imaginárias da Cidade da Bahia. Um Diálogo entre a Geografia e a Literatura (2004) e Imagens da Cidade da Bahia. Um Diálogo entre a Geografia e a Arte (2007), na visão daqueles estudantes e pesquisadores que retrataram e recontaram a Cidade do Salvador em suas múltiplas representações, por meio da relação e do elo entre a arte e o espaço geográfico.
\end{abstract}

Palavras-chave: Arte; Geografia; Salvador.

Resumen: La experiencia de la disciplina del espacio geográfico en la literatura, el programa de Maestría en Geografía de la Universidad Federal de Bahía, emocionante y placentera de diálogo entre la geografía y arte, se abordará en las obras visiones imaginarias de la ciudad de Bahía. Un diálogo entre la literatura y Geografía (2004) y de las imágenes de la ciudad de Bahía. Un diálogo entre Arte y Geografía (2007), a la vista de los estudiantes e investigadores que describían y relataron la ciudad de Salvador, en sus múltiples representaciones, a través de la relación y el vínculo entre el arte y el espacio geográfico.

Palabras clave: Arte; Geografía; Salvador.

Abstract: The experience of Discipline "Geographic Space in Literature", from the Master's Program in Geography, of the Federal University of Bahia, in the instigating and pleasurable dialogue between Geography and Art, will be approached in the works "Imaginary Visions of the City of Bahia". A Dialogue between Geography and Literature (2004) and Images of the City of Bahia. A Dialogue between Geography and Art (2007), in the vision of those students and researchers who portrayed and recounted the City of the Savior in its multiple representations, through the relationship and the link between art and geographic space.

Keywords: Art; Geography; Salvador.

\footnotetext{
${ }^{1}$ Professora Associada I da Universidade Federal da Bahia. Atua na área de Geografia Urbana, com ênfase em Salvador e sua área metropolitana. Foca, também, o Espaço Geográfico na Literatura e Arte, Memória Geográfica e Milton Santos: o homem e a obra. É também professora do Programa de PósGraduação em Geografia da UFBA, na disciplina $O$ Espaço Geográfico na Literatura e orientadora de mestrado e doutorado na área de Geografia, Literatura e Arte.
} 


\section{INTRODUÇÃO}

Geografia, Ciência... Arte. Novos olhares... A experiência da Disciplina O Espaço Geográfico na Literatura, do programa de Mestrado em Geografia, da UFBA, no instigante e prazeroso diálogo entre a Geografia e a Arte, será abordada, na visão daqueles estudantes e pesquisadores que retrataram e recontaram a Cidade do Salvador em suas múltiplas representações, por meio da relação e do elo entre a arte e o espaço geográfico.

Na obra Imagens da Cidade da Bahia. Um Diálogo entre a Geografia e a Arte (2007), a cidade do Salvador não se vê apenas percorrida pela Literatura: ampliouse para a arte. Far-se-á um passeio da Rua Chile à Rua da Praia, na Ladeira da Misericórdia de Godofredo Filho, na Baiana de Acarajé: de Personagem Cantada a Profissão, no conto È Natal! É Natal, de 1977, do escritor baiano Vasconcelos Maia, no Cinema da Geografia Soteropolitana.

A agora doutoranda Camila Xavier Nunes nos brinda com seu artigo intitulado “Caminhos da Memória: Um Passeio da Rua Chile à Rua da Praia”, materializado na Geografia da Rua. O poema de Mário de Andrade, "O mapa da Cidade", é evidenciado: “Olho o mapa da cidade/Como quem examinasse/A anatomia de um corpo...", onde a história de vida acontece com seus encontros e desencontros. Neste, também, observamse as ruas como artérias da cidade, onde a realização da vida se faz presente.

Nos seus áureos tempos, a Rua Chile era onde estavam localizadas as principais lojas, no requinte da Chapelaria Mercuri, da Casa Sloper, da Alfaiataria Londres e do Chapéu Parisiense, da Sala de Chás das Duas Américas, da Confeitaria Chile, dos famosos Cines Glória e Guarani, onde, na década de 40 e 50, exibiram-se as maiores bilheterias de Hollywood. Ponto de encontro de jornalistas, políticos, médicos, advogados e onde se sentia a importante vida boemia. Rua que acendia todo o seu glamour.

A Rua Chile passa por um processo de transformação, a partir da década de 1970, ocorrido em função, primeiramente pela transferência da maior parte das atividades administrativas do Estado da Bahia para o CAB, Centro Administrativo da Bahia, na Av. Luiz Viana Filho, também conhecida como Av. Paralela, numa das áreas de maior investimento do setor imobiliário na cidade. Destaca-se também a perda do papel comercial do centro para o novo modelo ideológico de modernização, os 
shopping-centers: o Shopping Iguatemi Salvador, em 1975, Shopping Piedade, em 1985, e Shopping Barra, em 1987, que alteraram a dinâmica comercial e de serviços no local. Ressalta-se, neste contexto, o descaso com a Rua Chile, durante o Processo de requalificação do Centro Histórico de Salvador. Ela foi apenas inserida durante a $7^{\circ}$ etapa do processo.

Além das mudanças no papel do Centro (tradicional) de Salvador, a reestruturação do espaço urbano impôs uma nova lógica na centralidade urbana e provocou o surgimento de novas áreas com papel de satisfazer os novos desejos e necessidades criadas para a população. Ao se percorrer a Rua Chile nos dias atuais sente-se melancolia, de lembranças e abandono. E Camila questiona se o futuro da Rua Chile será o mesmo que a "Mulher de Roxo"? Assim era denominada Florinda, personagem famosa, que, nos tempos áureos da Rua Chile, contrastava com seus trajes longos, veste de santa, com um crucifixo no pescoço e descalça. "Florinda morreu anônima e sem honras. Será esse o futuro da Rua Chile? Terá o coração da Cidade, deixado de bater?" (2007, p. 29).

Assim como a Rua Chile, revive-se Rua da Praia, considerada a mais ilustre da cidade de Porto Alegre em seus diferentes tempos. Uma rua de muita história, de muitos personagens. Dos importantes e elegantes cafés e confeitarias: Café Suissa, Café Florida, a Confeitaria Colombo, a Woltmann e a Tabacaria Condor. Nela, a livraria dos sonhos, a Livraria do Globo. e dos cinemas, o Cine Guarani, o Rex, o Cine Rio e o Imperial.

O tempo passa dando lugar a uma nova funcionalidade na cidade e os prédios são abandonados ou substituídos por outros mais funcionais de arquitetura moderna. Dá-se a transferência do grande centro comercial e de lazer para os shoppings centers, que começam a aparecer por toda a cidade. Inicia-se, então, no final da década de 1970, uma nova discussão sobre o patrimônio cultural da cidade, através do Projeto Corredor Cultural. O Hotel Majestic transforma-se na Casa de Cultura Mário Quintana e o antigo e belíssimo prédio da Companhia Força e Luz Porto-Alegrense abriga, agora, o Museu da Eletricidade do Rio Grande do Sul (Mergs) e o Centro Cultural Érico Veríssimo. Desta forma, a partir destas intervenções, a Rua da Praia ganha, novamente, vida.

Ao se reviver um pouco da história das ruas, Chile e da Praia, faz-se um convite à reflexão acerca da rua, não apenas em sua materialidade, mas, também, em sua 
essência, onde a realização da vida cotidiana se faz muito presente, impedindo que os acontecimentos se percam no fluir do próprio tempo. Pelo fato de a reprodução espacial estar fortemente associada à reprodução capitalista, ocorre a sensação de se viver sem referências. "Daí a importância do mito, do imaginário, do rito, da estética e da poesia, como meio de comungar e encantar-se com o espaço habitado e vivido, ultrapassando a funcionalidade racional do mundo mercadoria" (2007, p. 34).

Contemplou vários teóricos para este rico diálogo. Entre eles, Milton Santos, $A$ Natureza do espaço; técnica e tempo, Espaço e emoção; A Revolução Urbana de Lefebvre; Ana Fani Carlos com a obra $O$ espaço Urbano: novos escritos sobre a cidade, entre outros.

Maria Amélia Seabra Martins também nos presenteia com seu brilhante artigo "Ladeira da Misericórdia: Lugar "Perdido" no Espaço da Cidade de Salvador", no poema de Godofredo Filho, Ladeira da Misericórdia (1949), estabelecendo um rico cenário de relacionamentos entre os que moravam e trabalhavam nos casarios desta Ladeira. A atenção da aluna foi despertada diante de um espaço real, porém vazio de significados em seu imaginário. Através do poema, Godofredo Filho revela sua relação de profunda intimidade com aquele espaço, este vivenciado e experenciado pelo poeta. Godofredo nos conduz tanto à Ladeira da sua contemporaneidade, como a do passado, numa relação com o tempo e o espaço.

A partir da década de 1970, a Ladeira da Misericórdia sofre influencia do processo de esvaziamento do Centro Histórico de Salvador, com a mudança de sua centralidade, ocorrida em função da modernidade, o que levou à degradação econômica, física e social do centro antigo. Era também recanto da boemia, da animada vida noturna, dos espaços democráticos do passado. Mulheres que deram significado àquele espaço não mais o habitam.

A Ladeira continua perdida, não nos aspectos revividos pelo poeta, mas diante do abandono, da miséria, da tristeza, do medo e da exclusão social. Maria Amélia relata a figura de uma mulher que lavava roupa na fonte da ladeira. "Sua figura sem cor e sem vida se igualava a da Ladeira. Sua expressão, tal qual a da Ladeira, não pedia Misericórdia... pedia respeito, amor e atenção, pedia ação”. Assim, a Ladeira é a representação de outros tantos espaços perdidos nesta cidade e da desigualdade social da qual somos parte". Olho mais uma vez esta Ladeira, este lugar esquecido no espaço da 
Cidade de Salvador. "E, dessa vez, Godô, sou eu quem está perdida e pede Misericórdia!"' (2007, p. 47).

Anderson Carigé destaca a contribuição da baiana do acarajé para a construção da identidade da cidade no artigo "Baiana de Acarajé: de Personagem Cantada a Profissão". Desde o final do século XVIII, tem-se a presença da baiana do acarajé, perpetuada por seus descendentes afro-brasileiros, através da criação da sua cultura, que oferece uma riqueza incalculável. De aroma inconfundível, desperta o desejo e o encontro de moradores e visitantes às tradições do passado. A "nega baiana" foi cantada por Caymmi (1947): -Quem quiser vatapá - ô / Que procure fazer: / Primeiro o fubá, / Depois o dendê. / Procure uma nega baiana - ô / Que saiba - mexer, / Que saiba mexer, / Que saiba - mexer.

Caracteriza três categorias de baiana de acarajé: a baiana tradicional, que desenvolve sua atividade num determinado ponto da cidade, com um ajudante e em pontos menos privilegiados da cidade; a baiana da praia, que oferece seu acarajé ao lado de uma barraca de praia, com um ajudante e dependente da alta temporada e da situação climática; a baiana point, possui mais de dois ajudantes, já é pessoa jurídica ou possui parceiros comerciais. As baianas são acompanhadas por suas roupas tradicionais: a saia rodada, o torso na cabeça, a bata e os colares dos seus orixás pessoais... e por seus tabuleiros com acarajé e seus complementos - vatapá, caruru, a salada de tomate verde, o molho de pimenta bem picante, camarão seco, bolo de estudante, cocada branca e preta.

Ressalta que, em 1992, um grupo de 50 baianas fundou a ABAM (Associação das Baianas de Acarajé e Mingau), uma instituição associativa, comunitária e filantrópica, sem fins lucrativos, com sede nacional no Pelourinho e que, em 2007, já possuía 1850 associados, entre baianas e baianos, voltados para a profissionalização da atividade. O registro do "ofício das baianas de acarajé" como "patrimônio imaterial" ocorreu em 2004 pelo Instituto do Patrimônio Histórico Nacional, IPHN, reconhecendo oficialmente a relevância social e cultural das baianas, atribuindo um valor de patrimônio ao "bolinho dourado". O acarajé é uma palavra composta da língua iorubá "comer fogo" (ACará + ajeum), originária do Golfo de Benin. Trata-se de uma comida sagrada, utilizada em rituais do candomblé, nos quais é ofertada aos orixás, principalmente a Iansã e a Xangô. Assim, a tradição do acarajé com a figura da baiana 
do acarajé, associada aos seus encantos e magias, fazem parte da representação simbólica da cultura baiana.

Patrícia Pontes nos apresenta o conto É Natal! É Natal, de 1977, do escritor baiano Vasconcelos Maia, intitulado "Os que à Cidade não Pertence: Cidade e Exclusão nos Contos de Vasconcelos Maia". O conto revela a Cidade do Salvador na década de 60, período de grandes transformações na configuração espacial da cidade. Brito (1977) cita algumas destas mudanças: a mudança dos bondes pelos ônibus, em 1961; abertura das avenidas de vale; e a transferência do Centro Administrativo da Bahia do Centro Histórico para a Av. Luís Viana Filho (Paralela).

É estabelecida uma relação dos versos com a história da Cidade e delas com a importância das centralidades urbanas, que, segundo Castells (1983), esta centralidade expressa, ao mesmo tempo, um local geográfico e um conteúdo social. O autor destaca três níveis de análises importantes para a compreensão do papel das centralidades em uma cidade: o centro integrador e simbólico, o centro funcional e o centro lúdico.

Desta forma, verifica que o Centro tradicional de Salvador, a Avenida Sete e a Rua Chile concentravam, ao mesmo tempo, a funcionalidade, a integração e o lúdico. Leal (1996, p. 115) descreve o cotidiano desta rua: “As senhoras, suas filhas, estudantes, os intelectuais nas portas dos cafés faziam daquela rua a rua mais chic da cidade... Sem falar nos hotéis, cassinos, chás requintados, e o espelho da Livraria Civilização...”.

Este cotidiano da cidade, do "habitar a rua", está sendo substituído pelo espaço mercadoria: as cidades se reduzem a uma única e mesma cidade, cujas identidades se acham cada vez mais fragmentadas e contraditórias. Como lembra Carlos (2004, p. 62), a cidade como "espetáculo do consumo, as ruas redimensionam-se e ganham outro conteúdo que elimina o lúdico, pois se transforma, em lugar de passagem. As grandes lojas de departamento e os shoppings centers substituem o lazer, ou melhor, viram o lazer”. Também relatado no conto É natal! É Natal!: “A Avenida Sete chamava-o... sua frenética avidez da escolha dos presentes cupidamente expostos nas vitrines, que resplandeciam de luzes e cores - um mundo encantado de joias, roupas doces e brinquedos". 
Enfatiza que as cidades do consumo também são as cidades do individualismo, da exclusão e tomaram conta do espaço e do tempo, violentando lugares e pessoas... A cidade não é mais vista como local de encontro.

Rita de Cássia O. Rizério e Sandra R. F. Carrilho contemplam "O Cinema na Geografia Soteropolitana". Ressaltam que para o entendimento do movimento cinematográfico da Bahia é necessário entender o contexto histórico da época, situandoo no conjunto de fenômenos artísticos e sociológicos no tempo e no espaço. Destacam no Estado da Bahia a importante da descoberta do petróleo e a instalação da Refinaria Landulfo Alves, em Mataripe, na região metropolitana de Salvador para fim do isolamento baiano, sobretudo com a inauguração da rodovia Rio-Bahia, que liga Salvador à capital do país. O cinema transformou-se, assim, como a cidade do Salvador.

Existe uma polêmica sobre qual seria o primeiro curta-metragem baiano, Regatas da Bahia, do cineasta Diomedes Gramacho, ou Segunda-Feira do Bonfim, do cineasta José Dias da Costa, iniciado em 1910. Eles retrataram as manifestações da cultura popular. A produção cinematográfica no estado teve seus momentos difíceis, mas se destacaram no cenário nacional, despontando com grandes cineastas como Roberto Pires, Nelson Pereira dos Santos, Anselmo Duarte, Oscar Santana e o inesquecível Glauber Rocha.

Sobre a importância do cinema, Nascimento (1981, p. 23) infere que "o cinema tem feito pela captação e conservação da realidade mais do que qualquer outra arte ou técnica" e destaca que é "nas imagens dos filmes concentram-se os fatores que movem uma sociedade. $\mathrm{Na}$ própria linguagem escolhida pelos filmes ficam expressas assimilações e criações culturais". O estudo e a utilização do cinema pela ciência geográfica promovem um melhor entendimento do assunto abordado. A cidade passa a ser analisada como objeto de reflexão. O estudo da representação da cidade através do cinema é uma importante ferramenta didática para a compreensão sócio-espacial desta.

A seguir, os filmes analisados, tendo como foco o estudo da paisagem, relacionados de acordo com o ambiente: Feiras e centros de abastecimento, os filmes " $A$ Grande Feira", Roberto Pires, de 1961, e "Sol sobre a Lama", Alex Viany, 1962. Ambos ocorrem na Feira de Água de Meninos, em Salvador, onde houve um incêndio, tanto na realidade como na ficção; Pobreza urbana, "Comunidade do Maciel”, de Tuna Espinheira, 1975, ambientada no Centro Histórico de Salvador e "Cidade Baixa", de 
Sérgio Machado, 2005, ambientada na zona portuária a seus arredores; Imagens Soteropolitanas, "Entre o Mar e o Tendal", de Alexandre Robatto, 1952-53, documentário da pesca do xaréu na Baía de Todos os Santos.

Sobre a rotina dos homens nos saveiros no Recôncavo Baiano, "A Morte das Velas no Recôncavo", de Guido Araújo, 1970; "Superoutro", Edgard Navarro, 1989, e "Preto e Branco", de Joel de Almeida, 2000. Salvador ambientada em várias épocas, "Dona Flor e Seus Dois Maridos", de Bruno Barreto, 1976, filme baseado na obra de Jorge Amado, retratada na década de 1940; "O Corneteiro Lopes", de Lázaro Faria (2003), revive as batalhas pela independência da Bahia em 1823; e "Eu me Lembro", Edgard Navarro, 2005, nas décadas de 1950 e 1970; Religiosidade e festas populares, "Viva Dois de Julho", de Tuna espinheira, 1998, mostra a festa pelas ruas de Salvador em comemoração à independência da Bahia e "Oriki", de Jorge Alfredo e Moises Augusto, 2000, documentário sobre a festa de Iemanjá, no bairro Rio Vermelho, em Salvador; Intolerância religiosa ou cultural, "O Pagador de Promessas", de Anselmo Duarte, 1962, tem como principal cenário a Igreja dos Passos e sua escadaria e "Tenda dos Milagres", Nélson pereira dos Santos, 1977, ambos ambientados no Centro Histórico de Salvador.

Hoje, existem leis de incentivo à cultura e prêmios para projetos cinematográficos, o que tem permitido uma maior produção em curta, média e longa metragem. Mesmo assim, ainda é considerado um grande desafio fazer cinema no Brasil. A cidade, palco de narrar e produzir imagens, faz-nos refletir sobre uma série de questões sócias e urbanas vividas na tela e fora dela.

Na obra Visões Imaginárias da Cidade da Bahia. Um Diálogo entre a Geografia e a Literatura (2004), percorreu-se o mundo encantado e mágico das artes e de sua relação com a cidade do Salvador, nas expressivas criações romanescas de escritores baianos. Logo na apresentação do livro, o Professor Gervásio Rodrigo Neves compartilha que, ao percorrer as páginas de Visões Imaginárias da Cidade da Bahia, consegue ouvir Dorival Caymm, Jorge Amado e Castro Alves, os murmúrios nas ruas e nas ladeiras e do mar de Salvador, na "magia de Ítalo Calvino, na racionalidade de Walter Benjamin, e na razão e emoção de Milton Santos". Enfatiza ser "Um belo livro. Uma terna lição". 
"A Cidade de Salvador, dos idos de 1959: os olhares de Jorge Amado e Milton Santos", de Adriano B. Andrade, marca o ano de duas obras importantíssimas: "A morte e a morte de Quincas Berro D'água" e "O Centro da Cidade do Salvador". A Ciência e ficção aproximam ficção e realidade, contam histórias complementares, observam também suas diferenças e constata-se que as narrativas literárias, geográficas e históricas são formas diferentes de percepção do real.

A primorosa análise do Professor Milton Santos na sua tese de doutorado intitulada "O Centro da Cidade do salvador. Estudo de Geografia Urbana" vai muito além de uma mera visão positivista e fragmentada do espaço, com diversas considerações teórico-conceituais como: fixos e fluxos, estrutura e processos, circuitos formais e informais e discorre sobre a evolução da cidade, sua estrutura, fazendo referência ao Pelourinho, às funções do centro da Salvador e às funções portuárias.

A leitura de trechos da obra "A morte e a morte de Quincas Berro D'água" permite visualizar a territorialização no espaço banal, ou seja, o espaço do cotidiano, que, na concepção de Milton Santos (1996, p. 258), "a cidade grande é um enorme espaço banal, o mais significativo dos lugares. Todos os capitais, todos os trabalhos, todas as técnicas e formas de organização podem aí se instalar, conviver, prosperar”. Isto também pode ser comprovado nas obras de Jorge Amado que as escreveu tendo por base a vida, sua percepção e seu contexto. Com sua vivência, o autor mantém um diálogo íntimo com a configuração da cidade e com a realidade, transparente e nítida. $\mathrm{O}$ autor considera a cidade e as relações nela tecidas na produção de seu imaginário e das apropriações dos personagens que nela habitam e também a estrutura social e econômica da cidade do Salvador.

Nesse sentido, há de se ressaltar que a experiência e vivência do escritor Jorge Amado, que morou na adolescência na Ladeira do Pelourinho, num pensionato que funcionava num casarão, o 68, foram fundamentais para representá-la De forma íntima, descreve-a na obra Suor, publicada em 1934: "Chegou ao buraco do quarto e ficou olhando os telhados negros da cidade anciã. As ladeiras eram os braços da cidade esticados para o céu. Ali embaixo, no centro da ladeira empedrada ficava o Pelourinho, montado pelos colonizadores portugueses". E complementa que "Hoje, o Pelourinho desaparecera, mas a ladeira que lhe tomara o nome era como um pelourinho também. Todos os que ali viviam passavam vida apertada, sem pão, sem trabalho". 
Milton Santos apresenta também com muita riqueza, em detalhes, a vida nestes cortiços: "Nesses cubículos não há luz, nem ar e inexiste higiene. A vida nesses cortiços é um verdadeiro inferno e as diversas famílias que ocupam um mesmo andar se veem obrigadas a se servirem de um único banheiro e de uma só latrina”. E ainda descreve: "Escadas estragadas, paredes sujas, tetos com goteiras formam um quadro comum a toda essa zona de degradação" (SANTOS, 1959, p. 166).

A importância dos saveiros para o comércio local também foi contemplada pelos por Santos (1959, p. 73) ao afirma que "as necessidades da vida quotidiana acarretam outra função ao porto, a de receber os produtos de subsistência... O transporte de mercadorias faz-se por "saveiros", barcos à vela, cuja capacidade varia entre 12 e 15 toneladas" e por meio das sábias palavras de Jorge Amado (1959, p. 43), onde observa que “... aquele saveiro seria capaz de conduzi-lo mar afora, não para Maragogipe ou Cachoeira, ali pertinho".

A combinação de ficção e realidade científica nos converge num espaço simultaneamente geográfico e imaginário. E Salvador foi reflexivamente descrita por Milton Santos e Jorge Amado, o que vem confirmar o que eu e o Professor Délio Ferraz afirmamos: "sempre existiu uma íntima relação entre a literatura e a cidade", ou que "os escritores e poetas realizam um trabalho arqueológico, de busca da alma, da verdadeira essência da cidade" (PINHEIRO \& SILVA, 200, p. 5).

Janio L. de J. Santos, em "O imaginário da Cidade de Salvador nas canções de Dorival Caymmi - uma reflexão geográfica" nos traz uma análise da cidade de Salvador através da obra deste cantor e compositor baiano cujo tema principal é a exaltação da sua terra natal - a Bahia-, a partir da "leitura" de suas músicas, destacando-se a categoria espacial, o lugar.

Caymmi teve um importante papel na construção da imagem da cidade do Salvador, representada nas diversas formas culturais. A paisagem poético-musical de Caymmi tem o mar como uma das suas mais importantes fontes de inspiração. O mar não apenas como um elemento da natureza, mas também da sua relação com o seu povo, onde desfilam orixás, imagens, gentes, coisa e tudo que possa estar ligado à beleza das águas que banham Salvador. O mar este que é admirado, respeitado e amado. O mar como meio de agradecer as graças alcançadas, como na música "Dois de Fevereiro e festa de Rua": Cem barquinhos brancos / Nas ondas do mar / Uma galeota a 
Jesus levar / A Conceição da Praia está embandeirada / De tudo quanto é canto muita gente vem / Dia Dois de fevereiro. Dia de festa no mar / Eu quero ser o primeiro para salvar Yêmanjá.

A representação da mulher brasileira aparece na obra caymminiana: a "mulata", a "baiana", a "nega", a "preta" e a "morena". Em "O que é que a baiana tem?" revela o papel da mulher baiana: "Só vai no Bonfim que tem / Um rosário de ouro, uma bolota assim / Quem não tem balangandãs não vai no Bonfim”. Também ligada às tradições religiosas, como em "Santa Bárbara": "Santa Bárbara chegou, seu dia chegou / Tem pagode no mercado, tem pagode bom... / Na Baixa dos Sapateiros vai ter fuzuê". Citamse outras importantes canções: Lenda de Abaeté, Você já foi à Bahia?, Bahia com h, dentre tantas outras.

O estudo da cidade do Salvador através da música de Dorival Caymmi lança-nos no universo do cotidiano da cultura baiana, bem como no dos principais elementos naturais que compõem a paisagem. A aluna questiona-se em definir quem influenciou quem... "Se foi a cidade que deu margem ao imaginário de Caymmi, ou se foi ele que, através de seus versos, nos fez perceber a cidade à sua maneira". E conclui: “É uma visão romântica, sem dúvida nostálgica, de uma cidade mítica e complexa, mas também fortemente desigual" (PINHEIRO; SILVA, 2007, p. 138).

No artigo "Uma revisão literária da percepção dos lugares na cidade do Salvador", Suely dos S. Coelho descreve sua percepção da obra "Histórias de Salvador - Cidade da Bahia" (1996), de Geraldo da Costa Leal, baiano, nascido em 1923, no Distrito de Santo Antônio Além do Carmo, em Salvador. O escritor nos presenteia com um relato da experiência na cidade do Salvador, dos acontecimentos advindos entre os anos de 1920 a 1960, com destaque para a relação homem e meio ambiente. Busca compreender a cidade do Salvador, como lugar, nos estudos de Tuan. Para ele, o espaço transforma-se em lugar à medida que adquire significados e que os seres humanos sentem-se apegados ao lugar, mas desejam a liberdade, sugerida pela ideia de espaço. Desse modo, incorporou-se a possibilidade de, na literatura, a forma de o homem representar a sua experiência com o espaço ser utilizada como referência para os estudos geográficos à proporção que ela enriquece e completa a realidade e dualidade existente no espaço. 
Utilizar-se-á os conceitos e teorias desenvolvidas no âmbito da geografia humanística, ao priorizar as representações, percepções, imagens e atitudes do homem para com o mundo vivido. A abordagem da cidade pode ser feita através da literatura, no diálogo entre as vivências urbanas e a sensibilidade dos escritores. Para Tuan (1983, p. 180), "uma função da arte literária é dar visibilidade as experiências íntimas... chamar a atenção para as áreas da experiência que de outro modo passariam despercebidas".

A aluna também utilizou os conceitos de topofilia, que são os sentimentos de afeição ao lugar, ou de topofobia, de repulsa ao lugar, utilizados por Tuan. E de topocídio, contínuo processo de aniquilação deliberada de lugares, conceito preconizado pelo geógrafo britânico Porteous (apud AMORIM, 1996, p. 142). Cita também o de topo-reabilitação, que é restaurar os lugares, paisagens ou conjuntos ambientais. Repensar as práticas de requalificação, priorizando as especificidades do lugar, na manutenção da memória coletiva ou individual e da preservação da identidade cultural, elevaria o homem à condição de sujeito nesse processo.

Destacou a importância de alguns lugares e ambientes, que ainda estão presentes no imaginário coletivo dos habitantes da cidade do Salvador. Como o Teatro São João, localizado na Praça Castro Alves, inaugurado em 1812, frequentado pelos amantes da arte e palco de acontecimentos memoráveis, onde o poeta Castro Alves recitou "O Livro e a América", “Ode ao Dois de Julho" e "Quem dá aos pobres empresta a Deus"; O Teatro São João concretizou-se como elemento centralizador de sentimentos de topofílicos. Os saveiros, que traziam as mercadorias provenientes do Recôncavo baiano ao Mercado Modelo. Hoje, estes saveiros ainda podem ser apreciados no Clube do Saveiro, na Ribeira. O saveiro ainda enfrenta um topocídio. No entanto, a tentativa de mantê-lo preservado expressa uma tentativa de topo-reabilitação, ou seja, de resgate da topofilia; Os bondes que marcaram a vida urbana a partir de 1898, serviam de transporte de passageiros, mercadorias e cargas, serviços funerários e de festejos comemorativos, viveu esse período áureo até meados da década de 1940, perdendo espaço para os trólebus na década de 1950 e desativado em 1968 e, em seguida, para os ônibus. Segundo Sant'ana (1996, p. 131), “o bonde era uma coisa extraordinária, soberba, excepcional... Quando passava para o "Colégio Senhor do Bonfim" ou para a missa do padre Edmundo, na igreja da Penha, olhava pasmado para o bonde que passava. Parecia arte mágica". 
As transformações ocorridas no cenário urbano na cidade do Salvador, entre 1920 a 1960, como alargamento das vias, modernização no sistema de transportes, padrões habitacionais, conflitos e os interesses que se projetam no espaço urbano e na vida cotidiana, convertem-se numa constante e crescente tensão entre uma permanência material estilizada e uma profunda ruptura social, tristemente acompanhada da impossibilidade da vida urbana que lhe dava sentido. Vale aqui ressaltar a importância da memória como elemento da identidade e de pertencimento do morador ao seu lugar.

Estes foram alguns dos trabalhos produzidos pelos alunos da disciplina O Espaço Geográfico na Literatura neste fascinante e instigante desafio em pensar a Cidade do Salvador em suas múltiplas representações, penetrando por seus becos escusos, em suas ladeiras, no cotidiano de seu povo.

Cabe destacar a publicação Geografia, literatura e arte: reflexões que foi gerada pela produção acadêmica apresentada e discutida no I Simpósio Nacional de Geografia, Literatura e Arte, realizado em junho de 2010, estruturado com importantes contribuições de docentes e pesquisadores. O livro Geografia, Literatura e Arte toma forma em um contexto de crescente estudo sobre as reflexões que relacionam os campos de conhecimento da Geografia e da Arte, sobretudo da Literatura. Reúne 17 artigos de diferentes autores, expondo alguns estudos nesta perspectiva e propondo uma reflexão ampla sobre ela. A cidade de Salvador e centros, como o Pelourinho, estão diante de muitas destas reflexões, assim como o sertão semiárido nordestino, através do livro e filme Vidas Secas. Uma análise de Brasília, vista através das crônicas da escritora Clarice Lispector, é outra das reflexões apresentadas nos textos que compõem esta publicação.

Que a sensibilidade destes alunos e pesquisadores possa inspirar outros trabalhos nesta importante e desafiadora relação entre a arte, a geografia e a cidade. Esta última, como um palco de representações e elemento privilegiado da arte.

\section{REFERÊNCIAS}

AMADO, Jorge. A morte e a morte de Quincas Berro D'Água. Rio de Janeiro: Record, 2001.

AMORIM, F. Topofilia, topofobia e topocídio em Minas Gerais. In: DEL RIO, V.; OLIVEIRA, L. de. (Orgs.) Percepção ambiental: a perspectiva brasileira. São Paulo: Studio Nobe; São Carlos: Universidade Federal de São Carlos, 1996. 
BRITO. Cristóvão de C. da T. de. A Produção de Escassez de Terrenos Urbanos em Salvador e suas Consequências na Reprodução Futura do Espaço. Dissertação (Mestrado em geografia) - UFBA, Salvador, 1997.

CAYMMI, Dorival. Cancioneiro da Bahia. São Paulo: Livraria Martins Oliveira, 1947.

CARLOS. Ana Fani A. O espaço Urbano: novos escritos sobre a cidade. São Paulo: Contexto, 2004.

CASTELLS, M. A. Questão Urbana. Rio de Janeiro: Paz e Terra, 1983.

GODOLFREDO FILHO. Ladeira da Misericórdia. I: Irmã poesia: seleção de poemas (1923 - 1986) Rio de Janeiro: Tempo brasileiro, Salvador: Secretaria do estado de Educação e Cultura; Academia de Letras da Bahia, 1986.

LEAL, Geraldo da Costa. Histórias de Salvador: Cidade da Bahia. Salvador: (s.n.), 1996.

LEAL, Geraldo da Costa. Pergunte ao seu avô. Salvador, 1996.

LISPECTOR, Clarice. Brasília. In: Para não esquecer. Rio de Janeiro: Rocco, 1999. De corpo inteiro. São Paulo: Siciliano, 1992.

NASCIMENTO, Hélio. Cinema Brasileiro. Porto Alegre: Mercado Aberto, 1981.

PINHEIRO, D. J. F.; SILVA, M. A. da. (Orgs.). Imagens da cidade da Bahia: um diálogo entre a geografia e a arte. Salvador: Edufba, 2007.

Bahia: diálogos entre a geografia e a literatura. Salvador: Edufba, 2004.

Visões imaginárias da cidade da A Escrita das Cidades. Salvador:

MGEO - UFBA, 2001.

RAMOS, G. Vidas Secas. São Paulo: Record, 1989.

SANT’ANA, J. L. de. Bambangas (memórias). Salvador: FORMU; 1996.

SANTOS, Milton. A Natureza do espaço: técnica e tempo, razão e emoção. São Paulo: Edusp, 1996.

Universidade da Bahia, 1959.

O centro da cidade de Salvador: estudo de geografia urbana. Salvador: 
SILVA, M. A; SILVA, Harlan R. F. da. (Orgs.). Geografia, Literatura e Arte: reflexões. Salvador: Edufba, 2010.

TUAN, Y. Espaço e lugar: a perspectiva da experiência. São Paulo: Difel, 1983.

Recebido em 05/08/2018.

Aceito em 28/10/2018.

Publicado em 10/09/2020. 